ENSAYOS

\title{
POLITICA EDUCATIVA Y PROFUNDIZACION DE LA DESIGUALDAD EN CHILE
}

\author{
Educational Policy and deepening of unequality in Chile
}

\begin{abstract}
María Angélica Oliva
Instituto de Investigación y Desarrollo Educacional, Universidad de Talca, Campus Lircay s/n, Talca. moliva@utalca.cl
\end{abstract}

\begin{abstract}
"No renunciamos a la belleza e ilustradas certezas de la historia oficial, pero buscamos la emancipación de sus mitos, especialmente de aquellos que tienden a universalizar, homogeneizar y subsumir el conjunto de la sociedad real en el pseudoconcepto de 'lo chileno'. La idea de la "educación chilena" necesita despojarse de los velos que la cubren y que han tapado la diferencia, la exclusión, la separación y su propia negación”.
\end{abstract}

María Angélica Illanes 1991: 15.

"La educación se halla estrechamente vinculada con la construcción de una sociedad donde estén mejor distribuidas la riqueza, los recursos materiales y simbólicos, la 'buena' vida. La educación, aquí, debe ser construida como un espacio público que promueva esa posibilidad, como una esfera pública donde se construyan identidades sociales, coherentes con esa posibilidad".

Tomaz Tadeu da Silva 1998: 75.

\section{Resumen}

La desigualdad educativa se profundizó durante la dictadura militar en Chile. Después de 17 años del retorno a la democracia, la situación no ha remontado. Ello merece un análisis que, en este trabajo, es realizado desde la óptica deontológica, enfatizando tres aspectos: de la incidencia del conflicto entre Estado Docente y Libertad de Enseñanza y la desigualdad educativa en Chile; el rol del Estado subsidiario, una fractura en la educación como bien público y, finalmente, la Constitución de 1980 y la aplicación de la política neoliberal a la educación chilena.

Palabras clave: desigualdad educativa en Chile, ética y dimensión normativa de la actual política educativa chilena, dictadura y política educativa neoliberal en Chile, rol de Estado subsidiario en la educación chilena, Estado Docente versus Libertad de Enseñanza.

\begin{abstract}
The educational unequality became greater during Chile's militar dictatorship. Although seventeen years have passed after the return to democracy, the situation hasn't improved. This situation deserves being analyzed, which, in this piece of work is carried out from the "deontological" point of view, giving emphasis to three main aspects: conflict between Welfarestate ("Estado Docente") versus Freedom of Education ("Libertad de Enseñanza") and educational unequality; the role of the subsidiary state, a fracture upon educational as public wealth, and finally the 1980 Constitution and the enforcing of a neoliberal policy upon Chilean education.
\end{abstract}

Key words: educational unequality in Chile, ethics and ruling dimension of the present Chilean educational policy, Chile's dictatorship and neoliberal educational policy, role of the subsidiary State upon Chilean education, welfarestate ("Estado Docente") versus freedom of education ("Libertad de Enseñanza"). 


\section{INTRODUCCION}

Situar una reflexión en el dominio de la política educativa exige atender al carácter de la política y de lo educativo, a la configuración del espacio público y al sentido de la democracia, pues la acción política es la que hace posible y delimita el espacio público y la política de participación democrática es la que desplaza permanentemente sus límites incorporando, a los hasta entonces desconocidos, al todo que nos define. Es así como para Francisco Beltrán (2000) cabe entender que la política tiene que ver con la construcción del espacio público. Observemos cómo en esta concepción ética y política aparecen indisolublemente unidas, tal como plantea la tradición griega, pese a la fractura maquiavélica y a la actual preeminencia de la ética utilitarista, ligada a la colonización que el mercado realiza en los diversos ámbitos de la vida. Este trabajo rescata ese vínculo originario entre ética y política, para restituir el carácter moral de la educación, objeto de la política educativa. La ética permite analizar el grado en que una política educativa contribuye a fortalecer o, por el contrario, a debilitar el espacio público. La mentada relación, por un lado, entre ética y política y, por otro, entre ética y educación, señala la omnipresencia de la ética en la política educativa; ella constituye el leitmotiv del presente trabajo, que busca en la dimensión normativa de la política educativa una hebra para explicar por qué la desigualdad constituye no sólo una permanencia en la educación chilena, sino también, se radicaliza en la época actual, como un estigma que el tiempo de dictadura legara en el ordenamiento jurídico. Situar el análisis en el fenómeno jurídico permite atender a la convergencia entre el hecho social, el ordenamiento que lo regula, que determina derechos y obligaciones y focalizar la mirada en los valores que regulan lo anterior. Estos valores en el ámbito jurídico son, principalmente: justicia, bien común y seguridad jurídica. La justicia debe procurar el equilibrio entre derechos y obligaciones entendiendo que estos conceptos son antitéticos; el bien común persigue que el ordenamiento jurídico beneficie a toda la comunidad social y esté por encima de cualquier interés particular y, finalmente, la seguridad jurídica es la confianza que posee una comunidad en que el ordenamiento que la rige cumpla razonablemente con los dos valores anteriores. En este sentido, constituye el supremo valor jurídico (Millas 1970). Son, principalmente, estos tres valores jurídicos los que permiten enjuiciar el texto de la política educativa, en su contribución al fortalecimiento o detrimento del espacio público.

Lamentablemente, la desigualdad educativa es una de las lacras de la educación chilena, baste observar cómo a comienzos del siglo pasado es el problema central del debate ocurrido en la antesala de la promulgación de la Ley de Instrucción Primaria Obligatoria y Común (Chile, Ministerio de Instrucción Pública 1921). Tal desigualdad social y educativa queda caracterizada en la obra de Darío Salas (1917:5). El Problema Nacional. Bases para la reconstrucción de nuestro sistema escolar primario, que denuncia la existencia de un crimen colectivo, donde unos han participado como actores y otros como cómplices; este crimen es el problema de la pobreza ligado al altísimo nivel de analfabetismo existente en el país. Pretendemos ser democracia, señala el autor, sin embargo, "dejamos que la desigualdad de cultura perpetúe las diferencias de clase, mantenga la condición de siervos o de parias a una fracción importante de la sociedad y la condene a no vivir si no es con sujeción a normas de vida inferiores y a no apreciar el placer si no es en sus aspectos defectuosos o groseros".

El cambio de siglo nos encuentra reinaugurando la polémica que denuncia la profunda desigualdad educativa existente en el Chile de hoy, y son, precisamente, uno de 
sus protagonistas, los estudiantes de Enseñanza Media, quienes desnudan la crisis de la educación mostrando a su paso el déficit democrático de la sociedad. El impacto del movimiento estudiantil es significativo al situar en el centro del debate nacional lo que podríamos considerar una versión renovada del problema nacional, esto es, la desigualdad educativa como una de las manifestaciones de la desigualdad social. Mas, la denuncia muestra cómo la propia política educativa es cómplice del problema señalado. Baste observar la fractura que en el espacio público produce la institucionalización del rol subsidiario del Estado. La movilización estudiantil precipita la creación de un Consejo Asesor Presidencial para la Calidad de la Educación, cuyo trabajo aporta antecedentes para que la Presidenta de la República en su Mensaje de inauguración del actual período legislativo presente un Proyecto de Ley General de Educación, que revisa aspectos neurálgicos de la política educativa heredada del tiempo de dictadura. Interesa destacar, cómo en dicho Proyecto se refuerza el derecho a la educación, se vela por la igualdad de oportunidades, estableciendo medidas de discriminación positivas o compensatorias para reducir las desigualdades y se considera que la educación es un bien público y que, en ningún caso, puede ser un negocio, entre otros (CHILE Mensaje de S.E. la Presidenta de la República 2007).

En esta perspectiva, la pregunta que anima este trabajo es ¿De qué manera el ordenamiento jurídico y su concreción en la política educativa, desde la dictadura hasta la época actual, contribuye a profundizar la desigualdad educativa en Chile? El estudio de la pregunta permite vertebrar el trabajo en tres partes; se inicia la reflexión en el tiempo de larga duración Braudel (2002), para analizar la incidencia del conflicto entre el Estado Docente y la Libertad de Enseñanza en la construcción de la desigualdad educativa en Chile; a continuación, se muestra cómo la resolución de este conflicto a favor de la Libertad de Enseñanza y su articulación con el principio de subsidiariedad del Estado establece las bases jurídicas del orden neoliberal. Corolario de lo anterior, se muestra en la Constitución de 1980, que rige hasta hoy, el sentido de una transformación en el carácter de la educación, de ser un bien público a devenir en un producto de mercado o del tránsito de un ordenamiento jurídico que resguarda el derecho a la educación, a un ordenamiento jurídico que al replegar a la educación a la esfera privada, donde los padres tienen el derecho preferente y el deber de la educación, fomenta un orden social injusto una de cuyas notas dominantes es la desigualdad educativa. En este sentido, se plantea que la educación chilena necesita despojarse de los velos que la cubren y que han tapado la diferencia, la exclusión, la separación y su propia negación.

\section{DE LA INCIDENCIA DEL CONFLICTO ENTRE ESTADO DOCENTE Y LIBERTAD DE ENSEÑANZA EN LA CONSTRUCCION DE LA DESIGUALDAD EDUCATIVA EN CHILE}

\footnotetext{
"en esa primera y originaria significación parece que se ocultan, como una semilla, los posteriores brotes y ramificaciones"
}

Emilio Lledó 1996: 105.

¿Cuál es esa primaria y originaria situación donde es posible encontrar una raíz para explicar la persistencia de la desigualdad educativa en Chile? Para responder a este interrogante es necesario situarse con Braudel (2002), en el tiempo de larga duración, de las coyunturas y estructuras, que configura la historia profunda, antes que en el 
tiempo del acontecimiento, la histoire événementielle, que se queda en la superficie del tiempo. En cualquier análisis sobre Chile es necesario considerar su condición colonial, impronta de su historia; para el caso de la política educativa, parece válida la pregunta respecto de si esta condición constituye una estela o, más bien, se trata de un estigma para su posterior desenvolvimiento. Invasión, Encuentro, Descubrimiento, constituyen tres conceptos que desde diferentes ideologías han caracterizado el vínculo que entre dominadores y dominados se establece en Chile, tras la llegada de los españoles.

El proceso de emancipación, a instancias de las ideas ilustradas, llegadas también desde España, impulsa la fundación de un Estado Nacional Republicano, en cuyo desarrollo tiene gran influencia la educación, concebida como un deber primordial del Gobierno encargado de fundar una moral común (Chile 1833 Constitución Política de la República de Chile). Así se desarrolla una educación nacional, al amparo de la ley que regula la responsabilidad del Estado en materias educacionales.

En las tres primeras décadas de vida independiente, el Estado buscó principalmente resguardar, fomentar y controlar la red educacional existente de carácter: religioso, municipal y, en menor medida, estatal. El gobierno no tuvo ni los medios ni la intención de reemplazar la red educacional. El deber del Gobierno en la educación se concreta, por ejemplo, en que el Instituto Nacional es la institución matriz y modelo para el conjunto de la educación pública, al tiempo que la Universidad de Chile constituye el eje de la educación pública, con sus funciones de enseñanza y cultivo de las letras y de las ciencias y de superintendencia de educación, a cargo de la enseñanza pública y la inspección de todos los establecimientos de educación (Serrano 1994). Así, gradualmente, se configura la idea de un Estado Docente que recoge influencias internacionales, principalmente de Francia, Alemania y Estados Unidos, donde la educación es un deber del Estado y un derecho. Corolario de ello es la red de educación nacional, cuyo protagonista es el Estado, aunque también participan la iglesia y las comunidades locales.

Esta concepción de Estado Docente aparece estrechamente unida a la vida y obra de Valentín Letelier, miembro del Partido Radical y representante de la mesocracia, para quien la misión del Estado comprende funciones jurídicas y políticas (Letelier 1986, citado en Yáñez 2003: 51). En su obra de 1895, La lucha por la cultura, compilación de varios de sus escritos, adquiere forma su tesis del Estado Docente; destaca su discurso pronunciado en la Universidad de Chile, en septiembre de 1988, titulado El Estado y la Educación Nacional, donde sostiene, "Un Estado no puede ceder a ningún otro poder social la dirección superior de la enseñanza pública (...) para el sociólogo y para el filósofo bajo el respecto moral, gobernar es educar, y todo buen sistema de política es un verdadero sistema de educación, así como todo sistema general de educación es un verdadero sistema político" (citado en Riveros 2002: 2).

La noción de Estado Docente, que en sus inicios es laica y radical y luego es también liberal, entra en pugna con la postura católica y conservadora, partidaria de la Libertad de Enseñanza. ¿En qué consiste, en sus orígenes, la Libertad de Enseñanza? ¿Cuál es su sentido implícito y manifiesto? ¿Cómo se expresa a través del tiempo en los diferentes ordenamientos jurídicos? ¿Qué puede mostrar su enjuiciamiento desde una postura ético-jurídica?

En sus orígenes, el concepto de Libertad de Enseñanza consiste en la aspiración de asegurar a todos los colegios y, especialmente, a los pertenecientes a las congregaciones católicas la posibilidad de dar títulos y grados; fundamento de la autonomía de 
la enseñanza particular respecto de la tutela del Estado. De acuerdo a la función de la Universidad de Chile de superintendencia de educación, la Ley Orgánica de 1842 le otorga a su Facultad de Humanidades el derecho a fiscalizar los exámenes de quienes quisieran revalidar sus estudios, tarea delegada en los profesores del Instituto Nacional. En el gobierno de Federico Errázuriz Zañartu, que accede al poder apoyado por la fusión liberal-conservadora, esta facción condiciona su apoyo a la reforma en el sistema de exámenes para garantizar la Libertad de Enseñanza (Serrano 1994). Se nombra como Ministro de Instrucción Pública a Abdón Cifuentes, conocido detractor del Estado Docente, quien propicia la total libertad de los colegios particulares e impulsa la derogación de la normativa que supeditaba a la enseñanza particular a la tutela del Estado. Para ello, en 1872, firma un decreto que permite a cualquier colegio, ante sí y por sí, conceder validez oficial a los exámenes de sus alumnos. Con ello queda declarada la Libertad de Enseñanza (Labarca 1939). Retomemos, pues, la pregunta ¿cuál es el sentido, implícito y manifiesto, de la Libertad de Enseñanza? Las palabras de Cifuentes (1872) expresan en toda su contundencia el sentido de la defensa de la Libertad de Enseñanza contra la fiscalización estatal, "La libertad de enseñanza era un derecho natural de los padres de familia y un derecho político del ciudadano, como todas las libertades públicas" (citado en Serrano 1994: 233).

Finalmente, Cifuentes renuncia y el presidente Errázuriz rompe con los conservadores, revocándose el mentado decreto. La historiografía muestra diferentes interpretaciones sobre la resolución del conflicto mientras, por ejemplo, para Amanda Labarca (1939) el Partido Conservador logró, en los años 1872 y 1873, quebrantar al Estado Docente; para Sol Serrano (1993) ello representa un triunfo liberal, pues el Estado permanece en su fiscalización a la enseñanza particular. Con todo, los conservadores logran algunas prerrogativas para la enseñanza particular, como la autorización de algunos colegios particulares a dar exámenes en sus mismos establecimientos.

Queda de manifiesto, entonces, que Estado Docente y Libertad de Enseñanza ocupan los polos de un conflicto, donde hay dos posiciones que ideológicamente se contraponen: una educación dirigida por el Estado, laica y liberal, que privilegia lo público sobre lo privado, donde prevalece el derecho del Estado en la educación versus una postura católica y conservadora, que privilegia el derecho de cada familia en la educación, enfatizando lo privado sobre lo público.

¿Cómo se manifiesta este conflicto entre Estado Docente y Libertad de Enseñanza en los diferentes ordenamientos jurídicos? Cabe señalar que en su configuración y evolución participan tres Constituciones: la portaliana y conservadora, de 1833; la liberal y laica, de 1925, y la neoliberal y utilitarista, de 1980. Ellas aportan la normativa donde se desarrolla el conflicto conducente a la desigualdad educativa.

La Constitución de 1833 reconoce en la educación pública una atención preferente del Gobierno, al tiempo que establece el carácter católico del Estado chileno, pues Estado e iglesia están unidos. En el Capítulo XI. Disposiciones generales, se lee,

Artículo 153. La educación pública es una atención preferente del Gobierno. El Congreso formará un plan jeneral de educación nacional; i el Ministro del Despacho respectivo le dará cuenta anualmente del Estado de ella en toda la República.

Artículo 154. Habrá una superintendencia de educación pública, a cuyo cargo estará la inspección de la enseñanza nacional, i su dirección bajo la autoridad del Gobierno (Chile 1933 Constitución de la República de Chile: 243). 
En sus disposiciones transitorias, indica que para hacerse efectiva se dictará un conjunto de leyes, dentro de las cuales está la relativa al plan general de educación pública.

La Constitución de 1925 señala, por su parte, el término del régimen parlamentario; estipula la independencia del Poder Ejecutivo del Poder Legislativo, con lo que refuerza el Poder Ejecutivo. Junto a ello regula la separación de la iglesia y el Estado, con lo que signa las ancestrales luchas entre católicos y laicos. Respecto a la educación, en el capítulo Capítulo III, de sus Garantías Constitucionales, indica:

Artículo 10. La Constitución asegura a todos los habitantes de la República:

$7^{\circ}$ La libertad de enseñanza.

La educación pública es una atención preferente del Estado.

La educación primaria es obligatoria.

Habrá una Superintendencia de educación pública, a cuyo cargo estará la inspección de la enseñanza nacional y su dirección, bajo la autoridad del Gobierno (Chile 1925 Constitución de la República de Chile: 266).

Además, en la Constitución de 1925 hay una Ley, la $\mathrm{N}^{\circ} 17.398$, que modifica la Constitución Política del Estado, publicada en el Diario Oficial el 9 de enero de 1971, en el Proyecto de Reforma Constitucional, que señala,

6) Sustitúyese el $\mathrm{N}^{\circ} 7$ del artículo $10^{\circ}$ por el siguiente:

$7^{\circ}$.- La libertad de enseñanza.

La educación básica es obligatoria.

La educación es una función primordial del Estado, que se cumple a través de un sistema nacional del cual forman parte las instituciones oficiales de enseñanza y las privadas que colaboren en su realización, ajustándose a los planes y programas establecidos por las autoridades educacionales.

La Organización administrativa y la designación del personal de las instituciones privadas de enseñanza serán determinadas por los particulares que las establezcan, con sujeción a las normas legales (Chile 1925 Constitución de la República de Chile: 306).

Finalmente, en la Constitución de 1980: 23) en su capítulo tercero, De los derechos y deberes constitucionales (artículo 19:23),

$10^{\circ} \mathrm{El}$ derecho a la educación.

La educación tiene por objeto el pleno desarrollo de las personas en las distintas etapas de su vida.

Los padres tienen el derecho preferente y el deber de educar a sus hijos. Corresponderá al Estado otorgar especial protección al ejercicio de este derecho.

El Estado promoverá la educación parvularia.

La educación básica es obligatoria, debiendo el Estado financiar un sistema gratuito con tal objeto, destinado a asegurar el acceso a ella a toda la población.

Corresponderá al Estado, asimismo, fomentar el desarrollo de la educación en todos sus niveles, estimular la investigación científica y tecnológica, la creación artística y la protección e incremento del patrimonio cultural de la Nación.

Inciso $11 .^{\circ}$ La libertad de enseñanza incluye el derecho de abrir, organizar y mantener establecimientos educacionales.

La libertad de enseñanza no tiene otras limitaciones que las impuestas por la moral, las buenas costumbres, el orden público y la seguridad nacional. 
La enseñanza reconocida oficialmente no podrá orientarse a propagar tendencia político partidista alguna.

Los padres tienen el derecho de escoger el establecimiento de enseñanza para sus hijos (pág. 23).

Para comprender este conflicto entre Estado Docente y Libertad de Enseñanza es importante recoger la tesis de Mario Góngora (1988: 13), expuesta en su obra Ensayo sobre la noción de Estado en los siglos XIX y XX, donde señala que "el Estado es la matriz de la nacionalidad: la nación no existiría sin el Estado, que la ha configurado a lo largo de los siglos XIX y XX”, lo que indica cuál es el papel del Estado en la conformación de la identidad nacional y en la regulación y progresiva democratización de la vida pública chilena. En ese contexto y aunque con un sesgo autoritario, la Constitución de 1833 abre una ventana donde se patentiza la controversia entre conservadores y liberales. Para los primeros, el bien más preciado no es la libertad sino el orden, que para ellos se consigue con un gobierno fuerte. Mas, ¿cuál es el orden?, sin duda es el orden conservador, clerical, el de la reproducción social. Lo anterior permite observar cómo irrumpe la paradoja, pues su bastión de lucha es la Libertad de Enseñanza. ¿Cómo se entiende aquí la libertad? ¿Libertad para qué? ¿Qué distancia existe aquí entre las palabras y las cosas, que ellas nombran y significan? En cambio, para los liberales la libertad es la base de la prosperidad política. ¿En qué tradición se sustenta esa idea de libertad? ¿Tal vez no exista 'la libertad', sino que ella sea funcional a cada grupo y a sus propios intereses de dominación?

En la situación que nos ocupa, el peligro para los conservadores estaba en la inminente pérdida de la hegemonía de la iglesia católica en el ámbito educacional, pues en el Congreso Nacional el liberalismo ganaba terreno. El asunto cristaliza en una situación dicotómica: la aceptación o el rechazo del poder fiscalizador del Estado en materia educacional; los conservadores alegan que la Libertad de Enseñanza es un derecho natural de los padres de familia y un derecho político del ciudadano, en suma, una libertad pública. Los oponentes defienden e impulsan el deber del Estado de organizar un sistema educacional que fiscalice la enseñanza privada, para garantizar su calidad. En realidad, el fondo de la discusión estaba en dos concepciones ideológicamente contrapuestas sobre las relaciones de Estado y sociedad, enfatizando el tema educacional. La pugna inicial de liberales y conservadores se ahondó notablemente con la entrada en escena de los radicales y su necesidad de impulsar una educación laica, que los católicos asocian a la masonería.

Los ejes fundamentales del conflicto entre Estado Docente y Libertad de Enseñanza, tal como están regulados en las tres Constituciones permiten comprender cómo se ha construido la arquitectura de la desigualdad educativa en Chile, puesto que la desigualdad no está situada en el ámbito de lo 'natural' o 'dado', al contrario, se ha ido construyendo históricamente al hilo de las desiguales relaciones de poder, así como las condiciones de igualdad necesarias para el ejercicio de la libertad constituyen un derecho conquistado en el curso de las historia. Vemos, pues, profundas e irreconciliables diferencias respecto de los términos de la relación entre Estado Docente y Libertad de Enseñanza, que obstaculizan los consensos necesarios para articular un espacio público. Quizás, ello explique en algo la fragilidad de nuestra democracia; ésta sólo puede desplegarse en un espacio auténticamente democrático; plural por su propia conformación y pluralista 
por sus posibilidades de pervivencia. La educación marca aquí uno de los principales puntos de ficción; se radicalizan posturas respecto de ¿en quién recae el Derecho a la Educación, en la familia o en el Estado? ¿Cuál debe ser el contenido de la Libertad de Enseñanza, que finalmente regula las relaciones de poder entre lo público, representado por el Estado y lo privado, que representa la acción de los particulares? ¿Cuál debe ser el contenido de la Educación, laica o clerical? ¿Se debe educar para transformar la sociedad, o la sociedad debe dar las pautas para formar una educación a su medida?, en fin, ¿la educación debe ser un ejercicio para una práctica de la libertad o, más bien, para una práctica de sumisión? Lo anterior posee consecuencias de gran peso, pues el conflicto es condición necesaria para la conformación del espacio público y, precisamente, uno de los significados de la vida pública es construir una comunidad cuya identidad se sustente en la diversidad que representa, como sostiene Hannah Arendt (1993: 6):

Pues, si bien, el mundo común es el lugar de reunión de todos, quienes están presentes ocupan diferentes posiciones en él, y el puesto de uno puede no coincidir más con el otro que la posición de dos objetos. Ser visto y ser oído por otros, deriva su significado del hecho de que todos ven y oyen desde una posición diferente. Este es el significado de la vida pública.

Chile es un país que sabe de fracturas. Su estructura geológica asentada en el Cinturón de Fuego del Pacífico, unido a los movimientos tectónicos y diastróficos, le otorgan una perenne condición sísmica, sin embargo, nada es comparable a la fractura ocurrida en el tiempo de dictadura, que abarca todos lo ámbitos de la sociedad y produce consecuencias que signan, irremediablemente, el curso de su historia. Para el caso que nos ocupa, destaca la fractura en el espacio público, en la propia educación como bien público; la trasgresión de los valores jurídicos de justicia, bien común y seguridad jurídica; la mutación desde un valor consagrado a la educación como un bien público a su transformación en un producto de mercado. Su mecanismo, el principio de subsidiariedad, inherente de una concepción del hombre que se sustenta en el derecho natural. Este es, para el caso, uno de los posteriores brotes y ramificaciones de esa primaria y originaria significación del conflicto entre Estado Docente y Libertad de Enseñanza.

\title{
II. EL ROL DEL ESTADO SUBSIDIARIO. UNA FRACTURA EN LA EDUCACION COMO BIEN PUBLICO
}

\begin{abstract}
"Desde los inicios de los años setenta, y siendo su marco de origen la dictadura militar impuesta en Chile, luego del derrocamiento del gobierno constitucional de Salvador Allende, el programa de reformas impulsado por el neoliberalismo en América Latina se ha expandido progresivamente a casi todos los países de la región (...) Se trata, en definitiva, de transferir la educación de la esfera de la política a la del mercado, negando su condición (real o hipotética) de derecho social y transformándola en una posibilidad de consumo individual, variable según el mérito y capacidad de los consumidores"
\end{abstract}

Pablo Gentili 1997: 56 y 60.

La idea de la educación como un bien público posee una lata tradición en la historia de Chile, baste observar cómo desde la Constitución Política de 1833 se reconoce que la educación pública constituye una atención preferente del Gobierno. Esta tradición reconoce sus vínculos con la influencia francesa que la educación chilena experimentó 
por lo menos hasta el año 1880; las ideas del ideario pedagógico francés, por ejemplo: el derecho de todo ciudadano a la educación, el deber del Estado en materia de enseñanza y con la educación popular, la gratuidad de la educación elemental, el laicismo en la enseñanza e instrucción moral del pueblo, la idea de educación nacional y la responsabilidad del Estado en la formación del maestro, entre otras, constituyen el marco en que se inscriben los desafíos pedagógicos chilenos del siglo XIX (Conejeros 1999). También es posible destacar, entre otras, la tradición de la educación pública norteamericana, que define la escolarización como un bien público y un derecho fundamental; tal como queda de manifiesto en la obra de Dewey, que destaca la reciprocidad entre democracia y educación; la democracia constituye en sí misma un principio educacional, que no puede desarrollarse ni subsistir sin la educación, así, "La escuela constituye el agente esencial de la distribución de todos los valores y finalidades a que un grupo social tiende. No sólo es el único medio, sino el primero, el principal y el más específico de los medios por los cuales los valores a que tiende un grupo social y las finalidades que desea cumplir, se distribuyen y hacen familiares al pensamiento, la observación, el juicio y la elección del individuo" (Dewey 1961: 46).

El capítulo analiza cómo la resolución del conflicto entre Estado Docente y Libertad de Enseñanza, a favor de esta última, está en sintonía con la institución de un ordenamiento jurídico que permite el desarrollo del sistema neoliberal. En este contexto, la educación, que es un derecho y un bien público, termina transformándose en una mercancía y la vocación política de configurar una educación democrática cede a la vocación crematística de diseñar una educación tecnocrática ${ }^{1}$. ¿Por qué el conflicto que es condición necesaria para la vertebración de cualquier espacio público termina, en este caso, debilitándolo al extremo de producir una fractura imposible de subsanar? ${ }^{2}$. Conviene tener presente las condiciones en las cuales se resuelve tal pugna, esto es, el establecimiento de un régimen dictatorial, que accede al poder por la fuerza, transgrediendo el ordenamiento jurídico $\mathrm{y}$ violando los derechos fundamentales. Lo que ocurre, en realidad, es una pseudorresolución del conflicto, que origina múltiples puntos de fricción. Baste observar cómo, hasta el día de hoy, el Estado Docente es la bandera de lucha de los grupos laicos y progresistas y la Libertad de Enseñanza de grupos católicos y conservadores. Observemos, pues, cómo el principio de subsidiariedad, base del Estado Subsidiario, se articula con la Libertad de Enseñanza, pues poseen coincidencia en su ideología. ¿Cuál es esa ideología? ¿Cuál es la impronta que imprime en el texto de la política educativa, un régimen que por su propia naturaleza contraviene los valores jurídicos? ${ }^{3}$ ¿Es el principio de subsidiariedad un mecanismo que vulnera el valor asignado a la educación como un bien público y, a su paso, conculca el derecho a la educación? ¿Cuál es, finalmente,

1 Cabe señalar, que ya Aristóteles (1977) advirtió que al privilegiar el principio de beneficio sobre el principio de uso (economía doméstica) se corría el riesgo de culminar en el establecimiento de una sociedad crematística, esto es, orientada al lucro y fundada en la riqueza, que es justamente lo que caracteriza a nuestra sociedad que opera bajo el signo de un sistema neoliberal.

2 Esta pregunta recoge la idea expuesta por Francisco Beltrán (2000) en su obra Hacer pública la escuela, en cuyo capítulo VI desarrolla la tesis que la comunicación y el conflicto constituyen las condiciones de posibilidad para la conversión del espacio organizativo escolar en un espacio público.

3 La palabra impronta, es decir, marca o huella que, en el orden moral, deja una cosa en otra (RAE 2001: 1256), alcanza aquí su significado más propio, al permitir enlazar ética, política y educación. 
el orden que conforma ese régimen de facto en el texto de las políticas educativas que permanece hasta la época actual?

La génesis del principio de subsidiariedad del Estado, aplicado a la educación y su preeminencia, incluso hasta la época actual aparece, como se resaltó, con la violenta irrupción del régimen militar en la escena política y la instauración de la dictadura. Corolario de su idea de hombre y de sociedad, enunciada en la Declaración en los Principios del Régimen Militar, se sostiene que éste es el fundamento de la sociedad, con derechos naturales anteriores y superiores al Estado que arrancan de la propia naturaleza humana, pues poseen su origen en el creador; el Estado debe reconocerlos y reglamentar su ejercicio, pero no siendo él quien los concede tampoco podría jamás negarlos. El Estado, así concebido, debe estar al servicio del hombre y su fin es el bien común general, entendido como el conjunto de condiciones sociales que posibilite a todos y cada uno de los chilenos alcanzar su plena realización o bien personal (Chile, Gobierno de Chile 1974). Para el logro de esta aspiración, el Estado se vale de dos mecanismos, el derecho y el principio de subsidiariedad. Mas, ¿de qué derecho estamos hablando? ¿De qué derecho puede hablar un régimen de facto, cuando el topos ontológico del derecho debe ser buscado en su relación con el orden ético? (Ballesteros 1997). ¡Qué duda cabe! Este derecho se sustenta en el ius naturalismo, que postula la existencia de una ley que no emana de la voluntad humana, sino que procede de algo superior "que algunos piensan que es Dios, otros la naturaleza humana, otros la razón, y que, de todos modos, es superior al Derecho Positivo y sirve de fundamento a sus normas" (Pacheco Gómez 1988: 431). El principio de subsidiariedad señala, por ejemplo, que: "ninguna sociedad superior puede arrogarse el campo que respecto a su propio fin específico puedan satisfacer entidades menores, $y$, en especial, la familia, como tampoco puede invadir ésta lo que es propio e íntimo de cada conciencia humana" (Chile, Gobierno de Chile 1974: 17). Con ello, este principio impulsa el derecho a la propiedad privada y la libre iniciativa, ubicando a la educación en la esfera privada, pues es la familia su principal responsable, tal como lo señala, posteriormente, el texto constitucional del 80 , respecto del Derecho a la educación.

¿Qué sugiere que el derecho a la educación recaiga en la familia y no en el Estado? ¿Cómo se fractura la concepción de educación como un bien público, al replegar el derecho a la educación a la esfera privada? ¿De qué manera la clásica distinción de la tradición griega, entre la esfera privada o doméstica, ámbito de la necesidad y la esfera pública, ámbito de la libertad, otorga un buen punto de apoyo para develar el sentido de esta radical transformación en el derecho de la educación?

De modo que el principio de subsidiariedad determina un rol del Estado también subsidiario, que representa, para el caso, la clave de la vigencia de una sociedad auténticamente libertaria, pues a él le corresponde

asumir directamente sólo aquellas funciones que las sociedades intermedias o particulares no están en condiciones de cumplir adecuadamente, ya sea porque de suyo desbordan sus posibilidades (caso de la Defensa Nacional), las labores de policía o las Relaciones Exteriores o porque su importancia para la colectividad no aconseja dejar entregadas a grupos particulares restringidos (caso de los servicios o empresas estratégicas o fundamentales para la Nación), o porque envuelven una coordinación general que por su naturaleza corresponde al Estado (Chile, Gobierno de Chile 1974: 17). 
Pero nótese cómo el señalado principio respeta y promueve el derecho de propiedad privada, en la preeminencia de los derechos naturales que posee el hombre que son anteriores y superiores al Estado, lo que determina su rol subsidiario, que ejerce sustentado en el derecho y el principio de subsidiariedad, que regula y delimita los ámbitos en los cuales podrá tener una participación directa y activa, fomentando la participación de las iniciativas de los grupos privados. Ello significa un irrestricto respeto hacia la propiedad privada que se reafirma como uno de los pilares de la sociedad chilena.

En diciembre de 1975, según la resolución exenta $\mathrm{N}^{\circ} 3.102$, relativa a Difusión y cumplimiento de directrices contenidas en el documento "Objetivo Nacional de Chile", firmada por el dictador Augusto Pinochet Ugarte en su condición de General de Ejército y Presidente de la República, se aprueba este documento que contiene las metas fundamentales que guían la política general, inspirado en el principio básico de crear una nueva institucionalidad que proyecte hacia el futuro un régimen con metas claramente definidas y estables, enmarcadas en formas jurídicas que proporcionen una efectiva legitimidad de acción en todos los campos de la vida nacional. En lo relativo a objetivos en cada frente del país para avanzar hacia el objetivo nacional y dentro de las políticas específicas de desarrollo social aparece la educación, en cuyos principios orientadores se lee,

1) la educación deberá profundizar y transmitir el amor a la Patria y a los valores nacionales, el respeto a la vocación libre y trascendente del ser humano y a los derechos y deberes que de ella derivan, el aprecio a la familia como célula básica de la sociedad, la adhesión al concepto de la unidad nacional y la valoración del saber y la virtud como elemento de progreso del hombre y de la Nación.

2) Para cumplir con esa finalidad, el Estado reconoce el derecho preferente de los padres a educar a sus hijos, y admite una amplia libertad de enseñanza, sin otros límites que los que el bien común impone a la función educacional.

Ninguna libertad de enseñanza puede, sin embargo, contravenir los objetivos mismos de la educación. No se aceptará, por tanto, la difusión proselitista de ninguna doctrina o idea que atente contra la tradición o la unidad nacional, contra el sentido libertario y democrático de la institucionalidad chilena, o contra la integridad de la familia o de la nación. La educación no podrá ser usada con fines de política contingente.

3) El Estado considera como una de sus funciones más esenciales la de asegurar que la enseñanza básica obligatoria sea una realidad para todos los chilenos, proporcionándosela gratuitamente al menos a quienes no puedan subvenir económicamente a ella.

Asimismo, corresponde al Estado crear y mantener establecimientos educacionales en todos los niveles, en la medida en que la iniciativa particular sea insuficiente para cubrir las necesidades del país, proveyendo además al financiamiento subsidiario de la educación en general (Chile, Gobierno de Chile 1975: 48-49).

En sintonía con los documentos precedentes, en el año 1976, la Superintendencia de Educación formula un conjunto de principios rectores del sistema educacional fundados en la señalada idea de hombre, el rol del Estado subsidiario, el concepto de educación y las relaciones entre educación y cultura. Todo ello situado en la realidad chilena, que se nombra el contexto chileno. Se postula una idea de hombre, que está inscrita en el humanismo occidental con raíces cristianas "Para la cual el hombre es un ser trascendente cuya naturaleza espiritual le otorga primacía absoluta sobre todo lo creado, incluso respecto del Estado, porque los derechos de la persona humana son inherentes a 
su naturaleza que emana del propio Creador" (Chile MINEDUC 1975-1976: 14). Desde aquí se insiste en la idea de Estado subsidiario, cuya existencia se funda en este derecho natural para promover las condiciones necesarias al desarrollo integral de la persona y no para suplantarla en su acción, pues reconoce la preeminencia de sus valores por sobre toda organización, institución, poder o autoridad y también sobre el Estado y la sociedad. Desde aquí, se formula que el rol del Estado en educación consiste en: fomentar la iniciativa de las organizaciones privadas para que intervengan progresivamente en la gestión educacional, bajo orientación y apoyo de los órganos técnicos del Ministerio de Educación (Chile MINEDUC 1975-1976). La subsidiariedad es refrendada en los Principios de Acción del sistema educacional de la siguiente manera:

El Estado debe reconocer y apoyar la función educativa y cultural de la sociedad en su conjunto, manteniendo sólo el control necesario para la salvaguardia de los intereses públicos. Cuando se evalúen proyectos alternativos, se deberá tener en cuenta el papel jugado por la familia, la empresa, los gremios, las iglesias, las agrupaciones comunitarias y juveniles y en general la de aquellos que sin formar parte del sector público, promueven la Educación y la Cultura dentro de lo que suela llamarse "Ciudad Educativa" (Chile MINEDUC 1978: 10).

Repárese que el mentado rol subsidiario del Estado se ejerce mediante el derecho y el principio de subsidiariedad. Por ello es necesario atender al ordenamiento jurídico que concreta este nuevo rol del Estado, específicamente en la Constitución de 1980 y en la Ley Orgánica Constitucional de Enseñanza que refrenda la norma constitucional, tal como se analiza en el siguiente apartado.

Este principio de subsidiariedad y su corolario, la transformación del rol del Estado en la educación se manifiesta al menos en tres aspectos neurálgicos: el traspaso de la gestión de los establecimientos escolares, desde la dependencia ministerial centralizada a una descentralizada, la municipal; la transferencia de los docentes, de funcionarios públicos a municipales, y el cambio del sistema de financiamiento de la educación pública, desde un modelo basado en la oferta a uno basado en la demanda, estimulando la incorporación masiva de agentes privados (sostenedores) al mercado de la educación (Cox 2005; Donoso 2005).

He aquí cómo desde dos ejes de la política educativa, el jurídico y el de financiamiento, se sientan las bases para la profundización de la desigualdad educativa en Chile, tal como queda demostrado en un reciente estudio que refuta la hipótesis que la expansión de los establecimientos privados financiados con recursos públicos haya significado un mejoramiento de la educación chilena, en cuyas conclusiones se sostiene:

Basado en la evidencia y la literatura analizadas, mis conclusiones acerca del aporte de la expansión de la educación privada financiada por el Estado -en términos de resultados de aprendizaje- son las siguientes. Primero, las escuelas privadas subvencionadas -en promediono son más efectivas en producir resultados de aprendizaje que las escuelas públicas; más aún, si alguna diferencia existe, ésta parece favorecer a las escuelas públicas (dado que sabemos que las estimaciones han tendido a sobrevalorar el efecto de las escuelas privadas). Segundo, de existir alguna diferencia en la efectividad entre escuelas públicas y privadas (en cualquiera de los dos sentidos), es casi seguro que esta es de magnitudes muy pequeñas, sustantivamente irrelevantes. Tercero, en el mejor de los casos, la fuerte expansión de la educación privada subvencionada no ha provocado un mejoramiento apreciable de la calidad del sistema escolar chileno como un todo. Cuarto, existe evidencia que sugiere que la expansión de las escuelas 
privadas ha aumentado la segmentación y por esa vía la inequidad de la educación chilena (Bellei 2007: 18).

Se comprende, así, cuánta importancia tiene para este trabajo que el principio de subsidiariedad, funcional al establecimiento del orden neoliberal en Chile, quede tan bien articulado con la política curricular de casi una década anterior, mantenida y profundizada con el régimen militar. ¿Qué hay detrás del contubernio que se produce entre la arquitectura neoliberal de la dictadura y el currículum técnico que se instaura con la reforma de 1965? ¿En qué sentido ese modelo curricular se vincula con la profundización de la desigualdad educativa en Chile? ¿Cómo aparece en el lenguaje ‘científico’ y 'objetivo' que intenta colonizar el espacio escolar, debilitando a la institución educativa al quedar desprovista de su propio lenguaje?

Cabe señalar que la reforma de 1965 se realiza en el gobierno de la Democracia Cristiana encabezado por Eduardo Frei Montalva. Se trata de una reforma general del sistema educativo que se desarrolla en dos planos complementarios, que apuntan a: generar una expansión de las oportunidades educativas y a ejecutar transformaciones democrático-modernizantes en la estructura del sistema y de las prácticas educativas mismas (Núñez 1997). Esta reforma tiene dos fundamentos principales:

a) el desafío lanzado por la Alianza para el Progreso, que, a comienzos de los 60, convocaba a realizar fuertes transformaciones económicas y sociales en la región latinoamericana, tales como la reforma agraria, la reforma tributaria y también la reforma educacional, esta última a través de la moderna estrategia del "planeamiento integral de la educación" (planeamiento asociado al planeamiento económico y social, que se veía como la gran herramienta para superar el subdesarrollo de estos países) y b) la ideología del humanismo cristiano y el proyecto político englobado bajo la idea fuerza de la Revolución en Libertad (Núñez 1997: 9).

La reforma de 1965 considera el principio de la educación como una atención preferente del Estado, reafirmado en la Constitución de 1925 y hace posible la aplicación de los principios formulados con anterioridad en el país, tales como la educación integral del individuo, igualdad de oportunidades en el acceso a la educación y educación para la democracia. Del mismo modo, conserva el principio de la Libertad de Enseñanza, continuándose con los sistemas de educación pública y privada y el respeto a la autonomía universitaria. Conjuntamente, aparecen o se renuevan principios, tales como la: democratización de la educación, educación como atención preferente del Estado, educación permanente, educación para la vida, responsabilidad sociocultural de la educación, participación en el sistema educacional, educación para el cambio social y, finalmente, modernización de la educación (Castellón et al. 1979). Salta a la vista cómo varios de estos principios son contradictorios con su política curricular tecnicista, que transforma la educación en una ciencia aplicada, separándola de la filosofía y, especialmente, de la axiología, fracturando su auténtico carácter moral. Baste advertir que su modelo educativo, la pedagogía por objetivos, nace al amparo del eficientismo social y del entrenamiento industrial y militar, con claros vínculos con el movimiento utilitarista en educación, de comienzos del siglo XX en Estados Unidos, y con el enfoque taylorista, donde la industria como modelo de organización de producción se toma como patrón para la organización y el desarrollo curricular (Gimeno 1997). Ello muestra "una posición conservadora que ve en la educación y en la técnica del desarrollo de la enseñanza un 
instrumento eficiente, una tecnología, al servicio de la reproducción social" (Gimeno 1997: 19). Este modelo, cuyo propósito es tecnificar el proceso educativo, introduce un lenguaje ad hoc, que se dota de los atributos de 'objetividad' y 'neutralidad', con lo que enmascara su ideología, replegando y suplantando el lenguaje, propiamente educativo, que posee un carácter histórico y se sustenta en una tradición. Este lenguaje, a menudo, se constituye en una jerga que envuelve y confunde el espacio educativo reemplazando a la ética por recetas tecnocráticas.

Retomemos, pues, la pregunta ¿qué hay detrás de la alianza que se produce entre la arquitectura del orden neoliberal de la dictadura y el currículum técnico que se instaura con la pedagogía por objetivos en la reforma de 1965? Sin duda, es una manifestación de un estigma de nuestra perenne condición colonial, que no sólo nos ha situado en una condición subdesarrollada, sino, también, ha contribuido a la desigualdad educativa. En el sentido indicado, la reforma del currículum colaboró a la profundización de la desigualdad educativa en Chile, al fracturar profundamente el carácter moral de lo educativo, asestando un golpe fatal, para ilustrar con un ejemplo a uno de sus protagonistas, los profesores, a quienes a instancias de una "racionalidad técnica" se intentó transformar en técnicos, cercenándoles sus posibilidades de formar una comunidad reflexiva, consciente de la dimensión ética y política de su función profesional.

\title{
III. DE COMO LA CONSTITUCION DE 1980 PERMITE LA APLICACION DE LA POLITICA NEOLIBERAL A LA EDUCACION CHILENA
}

\begin{abstract}
La educación debe ser pensada como un bien sometido a las reglas diferenciales de la competencia. Lejos de ser un derecho del que gozan los individuos dada su condición de ciudadanos, debe ser transparentemente establecida como una oportunidad que a los individuos emprendedores, a los consumidores "responsables", se les presenta en la esfera de un mercado flexible y dinámico (el mercado escolar)
\end{abstract}

Pablo Gentili 1997: 60.

El principio de subsidiariedad y su aplicación a la política educativa se ajusta, plenamente, a las estrategias de reforma educativa orientadas al mercado que comprenden principalmente: la expansión de las escuelas privadas vía financiamiento público, la introducción de mecanismos de competencia (por matrícula, por recursos, por premios) entre las escuelas financiadas con recursos públicos, el uso de mecanismos de subvención tipo vouchers; el cobro de aranceles a las familias y la ampliación de las posibilidades de las familias de elegir la escuela de sus hijos (Torres 2001; Almonacid 2001; Bellei 2007). Vemos, pues, que en la Constitución vigente en Chile desde el año 1980 se advierte una clara intención de privilegiar al ámbito privado sobre el público. Por ejemplo, en su inciso 10, relativo al derecho a la educación hay dos claras señales que lo manifiestan,

La educación tiene por objeto el pleno desarrollo de las personas en las distintas etapas de su vida.

Los padres tienen el derecho preferente y el deber de educar a sus hijos. Corresponderá al

Estado otorgar especial protección al ejercicio de ese derecho (...)

Es deber de la comunidad contribuir al desarrollo y perfeccionamiento de la educación (CHILE Constitución de 1980: 23). 
Repárese en que el tono, el sentido y la intención muestran una contraposición con lo manifestado en la Constitución de 1925, su antecesora. En ella, según vimos, se enfatiza el rol del Estado y se usa la nomenclatura de educación pública; ésta es una atención preferente del Estado. Más aún, en la Ley $\mathrm{N}^{\circ} 17.398$ modificatoria constitucional bajo la rúbrica de Libertad de Enseñanza señala, de manera inequívoca, que la educación es una función primordial del Estado, que se cumple a través de un sistema nacional del cual forman parte las instituciones oficiales de enseñanza y las privadas que colaboren en su realización, ajustándose a los planes y programas establecidos por las autoridades educacionales (Chile 1925 Constitución Política de la República de Chile), tal como se indicó en el apartado anterior, donde el énfasis está puesto en la educación con el apellido de pública. Mas, es el inciso 11 de la Constitución de 1980 el que signa, expresamente, esta diferencia al interpretar el concepto de Libertad de Enseñanza, de la siguiente manera:

La libertad de enseñanza incluye el derecho de abrir, organizar y mantener establecimientos educacionales.

La libertad de enseñanza no tiene otras limitaciones que las impuestas por la moral, las buenas costumbres, el orden público y la seguridad nacional.

La enseñanza reconocida oficialmente no podrá orientarse a propagar tendencia político partidista alguna.

Los padres tendrán el derecho a escoger el establecimiento de enseñanza para sus hijos (Chile 1980 Constitución Política de la República de Chile: 23).

Ciertamente, se dejan abiertas las puertas para que la educación quede en manos de los privados, dando la espalda a la tradición republicana de casi dos siglos, que reconoce a la educación como una atención preferente del Estado. Ello representa una continuidad con la normativa impulsada por el Ministro Abdón Cifuentes, casi dos siglos antes. Cuestión que irá más lejos al consolidarse el rol del Estado subsidiario. Esta suerte de privatización cerrará el circuito con la Ley N 18.962 Ley Orgánica Constitucional de Enseñanza, LOCE, publicada en el Diario Oficial el 10 de marzo de 1990, cuyo artículo tercero señala que el Estado tiene el deber de resguardar, especialmente, la libertad de enseñanza (Chile MINEDUC 1990 Ley $\mathrm{N}^{\circ}$ 18.962).

La señalada transformación en el rol del Estado constituye el caldo de cultivo para la profundización de la desigualdad educativa en Chile; en 1981 se produce una transformación radical en el sistema educacional chileno, conocido como 'gran reforma educativa neoliberal'; se cambia, como ya se indicó, el sistema de financiamiento de la educación pública en todos los niveles, así como el sistema de contrato y dependencia de los profesores, cristalización del principio de subsidiariedad del Estado aplicado a la educación; proceso conocido como la municipalización de la educación. Ello constituye una de las siete modernizaciones del Estado, en pro de constituir un nuevo orden neoliberal, inspirado por las ideas de Friedrich von Hayeck y Milton Friedman, inspiradores intelectuales del proyecto capitalista impulsado por la dictadura chilena (Nef 2000).

Queda, así, regulada una metamorfosis de la educación, de ser un derecho público a transformarse en un producto de mercado, al tiempo que es trazado el derrotero para la profundización de la desigualdad educativa. Tal como ilustra Jorge Nef (2002: 2): 
La transformación de una concepción de "Estado Docente" a una de "Estado Subsidiario" en el caso chileno no fue resultado de una evolución progresiva o de un debate público; ni siquiera de la acumulación de insalvables contradicciones internas que llevaron a la ruptura de un paradigma educacional y su reemplazo por otro. Inequívocamente, el cambio de modelo educacional fue una consecuencia directa de, un cambio radical, rupturista y forzoso de un proyecto de sociedad a otro: de una democracia liberal con un Estado intervencionista a un régimen dictatorial con una economía neoliberal. Por lo tanto, para entender los cambios educacionales es menester analizarlos en el contexto de la contrarrevolución neoliberal de los años 70 y 80, cuyos efectos se han proyectado hasta nuestros días. Dicha contrarrevolución no fue un fenómeno limitado al ámbito chileno, aunque sus manifestaciones particulares, vigencia y proyecciones aparecen particularmente profundas y persistentes en nuestra república.

En esta metamorfosis es posible identificar a algunas de sus víctimas, por ejemplo, los profesores cuya profesionalidad aparece históricamente ligada al Estado Docente. Estos pierden su condición de funcionarios públicos y se transforman en empleados particulares "dependiendo de precarios contratos de prestaciones de servicios con los municipios y de la aquiescencia política de grupos pro régimen entronizados en la burocracia municipal" (Nef 2002: 5). También serán sus víctimas los estudiantes y sus familias, al sufrir el impacto del déficit en la calidad en su educación y su corolario en la ruptura de la ancestral función de movilidad social de la educación.

Esta nueva estructura del sistema educacional comienza con el mentado traspaso de la hegemonía de la educación pública del Ministerio de Educación a los municipios; de manera que la municipalización constituye el primer paso hacia la privatización.

El retorno a la democracia, sin embargo, significó la consolidación del sistema neoliberal. Para comprender mejor esta involución hay que realizar una radiografía de la LOCE. En su título preliminar Normas Generales y Conceptos se consolida la intención de privilegiar la educación privada, al reiterar en el artículo 3, lo dicho en la Constitución: "El Estado tiene, asimismo, el deber de resguardar especialmente la libertad de enseñanza. Es deber del Estado financiar un sistema gratuito destinado a asegurar el acceso de la población a la enseñanza básica" (Chile MINEDUC 1990 Ley N 18.962: 612). Esto permite poner en práctica el principio de subsidiariedad mediante la municipalización y el cambio en el sistema de financiamiento de subsidio por alumnos o subsidio a la demanda (Cox 2005; Donoso y Schmal 2002). Se evidencia el tránsito de la educación, desde el Estado Docente en el cual era claramente reconocida como una manifestación de bien común, a la Libertad de Enseñanza que la transforma en un producto de mercado bajo la tutela del Estado. Esto significa el abandono estatal de la educación, perdiendo su condición de bien común, ligado a su condición pública, que exigía una atención preferente del Estado. Así, el proceso de creación de mercados educacionales se concreta en cuatro tipos de establecimientos educacionales: establecimientos municipales, colegios particulares subvencionados, colegios particulares pagados y corporaciones educacionales dependientes de organizaciones empresariales (Almonacid 2001).

El título II de la LOCE es por sí solo elocuente y patentiza el giro neoliberal que impera en lo sucesivo. He aquí el reconocimiento oficial del Estado a establecimientos que impartan enseñanza en los niveles básico y medio. El artículo 21 radicaliza el giro neoliberal:

El Ministerio de Educación reconocerá oficialmente a los establecimientos educacionales que impartan enseñanzas en los niveles básico y medio, cuando así lo soliciten y cumplan con los siguientes requisitos: 
Tener un sostenedor, que podrá ser una persona natural o jurídica, que será responsable del funcionamiento del establecimiento educacional. Dicho sostenedor o representante legal, en su caso, deberá a lo menos contar con licencia de educación media (Chile MINEDUC 1990 Ley $\mathrm{N}^{\circ}$ 18.962: 619).

Esta figura del sostenedor representa la apertura de la educación al mercado, vale decir, la educación se puede convertir en un negocio lucrativo, en sintonía con el sistema neoliberal.

En el plano de la Educación Superior, el Título III de la LOCE establece el reconocimiento oficial del Estado a las instituciones de Educación Superior. Los artículos 29 y 30 consolidan la apertura de la educación superior al mercado, ampliando el área del negocio educacional con: la creación de las universidades privadas, del Consejo Superior de Educación y el Sistema de Acreditación, que agrega un nuevo componente al negocio educacional, donde se involucra a las universidades estatales existentes, tanto a las tradicionales como a las derivadas, producto de la desmembración de la Universidad de Chile y la transferencia de la Universidad Técnica del Estado, dado que la acreditación estará en sus manos, lo que proporciona ingresos monopolizados por el Consejo Superior de Educación, de acuerdo a aranceles fijados en el artículo $\mathrm{N}^{\circ} 38$.

En el párrafo $6^{\circ}$ de su título III, la LOCE regula el reconocimiento de los títulos y grados que otorgan los establecimientos de educación superior de las Fuerzas Armadas y de Orden dependientes del Ministerio de Defensa Nacional. Dentro de este párrafo, su artículo 74 lleva las cosas al límite, "Los Comandantes en Jefe de Fuerzas Armadas y el General Director de Carabineros podrán reconocer y convalidar los estudios aprobados y los títulos y grados académicos obtenidos en instituciones o universidades extranjeras, previo informe favorable del organismo superior de educación del nivel institucional que corresponda" (Chile MINEDUC 1990 Ley N 18.962: 641).

Ello, sin duda, refleja el grado de servidumbre de los que redactaron la Ley. Sin embargo, este artículo es, posteriormente, declarado inconstitucional por el Tribunal Constitucional por una sentencia de febrero de 1990.

Todas estas consideraciones indican que la educación deja de ser un bien común, es decir, esencialmente pública y de atención preferente del Estado; ello significa, en lo esencial, la pérdida de su sentido ético-jurídico, esto es, la expresión de un derecho y un valor. El quiebre de una tradición que otorga una primacía de los valores democráticos sobre la cultura empresarial y los valores comerciales (Giroux 2003).

Por la vía de la municipalización y expansión del sector privado, se convierte a la educación en un bien mercantil que persigue un afán de lucro en todos los niveles de enseñanza. Las universidades, por ejemplo, incorporan a la banca al negocio con el crédito bancario fiscal o privado, crédito que se entrega a los estudiantes que no disponen de los medios para financiar su educación superior. Todo ello al amparo de la Constitución Política de 1980, que al final de la dictadura es refrendada en la LOCE 1990, última jugada de Pinochet antes de entregar el poder. Situación que se mantiene, lamentablemente, en los gobiernos democráticos posteriores que, al igual que la dictadura, suscriben el sistema neoliberal.

Planteamos, con Braudel (2001), que el tiempo corto o del acontecimiento es engañoso, pues explica poco de los movimientos históricos; el tiempo largo, en cambio, permite mostrar el modus operandi de la desigualdad educativa en Chile, situarse en 
las permanencias, por ejemplo, del orden jurídico y financiero, para observar la conformación del orden neoliberal. Tal vez, sea adecuado recoger la tradición griega que junto con mostrar que todo cambia, señala que hay algo que parece permanecer, esto es, se resiste a sus propios cambios. ¿Qué es aquello que permanece y se resiste a sus propios cambios? ¿Cuál es ese tiempo de anchura secular que cambia poco? Sin duda, la respuesta a estos interrogantes invita a reflexionar en la idea de orden social; su conformación al hilo de la dimensión institucional de la cultura, en las históricas relaciones de poder y la consiguiente estructura de dominadores y dominados que han signado el curso de la historia.

Ha sido el espíritu de este trabajo analizar la construcción de la desigualdad educativa en Chile y, a su través, señalar algunos obstáculos que han impedido que la educación chilena contribuya a la construcción de una sociedad donde estén mejor distribuidas la riqueza, los recursos materiales y simbólicos, la "buena” vida.

\section{REFERENCIAS}

Almonacid, C. (2001). Creación de los mercados de la educación en Chile. Cuadernos de Pedagogía $\mathrm{N}^{\circ} 308$, volumen 1, diciembre. Barcelona: 65-70.

Arendt, H. (1993). La condición humana. Barcelona: Editorial Paidós.

Aristóteles. Política. En Obras. VII. Madrid: Aguilar Ediciones. Traducción del griego, estudio preliminar, preámbulo y notas por Francisco de P. Samaranch. Libro I, 1977: 1411-1571.

Ballesteros, J. (1997). Sobre el sentido del derecho. Introducción a la filosofía jurídica. Madrid: Editorial Tecnos.

Bellei, C. (2007). Expansión de la educación privada y mejoramiento de la educación en Chile. Evaluación a partir de la evidencia, Pensamiento Educativo. Santiago de Chile. Facultad de Educación. Pontificia Universidad Católica de Chile (En proceso de publicación).

Beltrán, F. (2000). Hacer pública la escuela. Santiago de Chile: Lom ediciones.

Braudel, F. (2002). La larga duración. En F. Braudel, Fernand. Las ambiciones de la historia (pp. 147-177). Barcelona: Editorial Crítica.

Castellón, G. et al. (1979). Las orientaciones educacionales en el sistema escolar chileno en 1965 y 1974-1978: Un enfoque sistémico. Seminario para optar al Título de Profesor de Historia, Geografía y Educación Cívica. Santiago de Chile: Escuela de Educación. Pontificia Universidad Católica de Chile. Profesor Guía Andrés Guzmán.

Castoriadis, C. (1995). La democracia como procedimiento y como régimen. Leviatán $\mathrm{N}^{\circ} 62$ : 65-83.

Conejeros, J. P. (1999). La influencia cultural francesa en la educación chilena, 1940-1880. Santiago de Chile: Ediciones Universidad Católica Cardenal Raúl Silva Henríquez.

Cox, C. (2003). Las políticas educacionales de Chile en las últimas dos décadas del siglo XX. En C. Cox (ed.). Políticas educacionales en el cambio de siglo. La reforma del sistema escolar de Chile. Santiago de Chile: Editorial Universitaria: 19-114.

Chile. Año 1833. Constitución Política de la República Chilena. Jurada y promulgada el 25 de mayo de 1833. En Diario Oficial de la República de Chile. Constituciones Políticas de la República de Chile 1810-2005. Santiago de Chile: Editado por el Diario Oficial de la República de Chile con el patrocinio del Ministerio del Interior, s/f.: 221-263.

Chile. Año 1925. Constitución Política de la República Chilena. Sancionada el 18 de septiembre de 1925. En Diario Oficial de la República de Chile. Constituciones Políticas de la República de Chile 1810-2005, Santiago de Chile: Editado por el Diario Oficial de la República de Chile con el patrocinio del Ministerio del Interior, s/f.: 264 a 316. 
Chile. Gobierno de Chile (1974). Declaración de Principios del Gobierno de Chile. Santiago de Chile: Editorial Gabriela Mistral.

Chile. Gobierno de Chile (1975). Resolución exenta N³.102. Objetivo Nacional de Chile. Difusión y cumplimiento de directrices contenidas en documento "Objetivo Nacional de Chile". Santiago de Chile, 23 de diciembre.

Chile. Ministerio de Educación Pública (1975-1976). Superintendencia de Educación. Políticas Educacionales del Gobierno de Chile. Santiago de Chile: MINEDUC.

Chile. Ministerio de Educación Pública. Superintendencia de Educación (1978). Política educacional y cultural del gobierno de Chile. Documento de Trabajo, Santiago de Chile: MINEDUC.

Chile. Ministerio de Educación. Ley No 18.961. Ley Orgánica Constitucional de Enseñanza LOCE. Publicada en el Diario Oficial de 10 de marzo de 1990. En Apéndice de la Constitución Política de la República de Chile. En República de Chile (2002). Constitución Política de la República de Chile (611-647). Santiago de Chile: Editorial Jurídica de Chile.

Chile. Mensaje de S.E. la Presidenta de la República con el que inicia un Proyecto de Ley que establece la Ley General de Educación (2007) Santiago de Chile, 9 de abril de 2007. Mensaje $\mathrm{N}^{\circ}$ 55-355. Disponible en http://www.mineduc.cl (Consultado 11 de abril de 2007).

Chile. Ministerio de Instrucción Pública. Lei de Instrucción Primaria Obligatoria Memoria del Ministerio de Instrucción Pública presentada al Congreso Nacional de 1921. En Monsalve, M. (1998). “....I El silencio comenzó a reinar” Documentos para la historia de la instrucción primaria 1840-1920. Fuentes para la Historia de la República. Volumen IX (218-231). Santiago de Chile: Ediciones de la Dirección de Bibliotecas, Archivos y Museos DIBAM.

Chile (2002). Constitución Política de la República de Chile. Santiago de Chile: Editorial Jurídica de Chile.

Chile. Diario Oficial de la República de Chile. Constituciones Políticas de la República de Chile 1810-2005. Santiago de Chile: Editado por el Diario Oficial de la República de Chile con el patrocinio del Ministerio del Interior, s/f.

Dewey, J. (1961). El hombre y sus problemas. Buenos Aires: Editorial Paidós.

Donoso, S. y R. Schmal (2002). Elementos para definir una política de financiamiento de la educación pública, Revista Pensamiento Educativo. Santiago de Chile: Facultad de Educación. Pontificia Universidad Católica de Chile (256 a 282).

Donoso, S. (2005). Balance y perspectivas de la reforma educativa chilena en los 90, Pro-posicoes $\mathrm{N}^{\circ}$ 3. Facultad de Educación de la Universidad Estadual de Campinas UNICAMP. v. 16 septiembre-diciembre: 29-52.

Gentili, P. (1997). El consenso de Washington y la crisis de la educación en América Latina, Archipiélago $\mathrm{N}^{\circ}$ 29. Barcelona: 56-65.

Gimeno Sacristán, J. (1997). La pedagogía por objetivos. Una obsesión por la eficiencia, Madrid: Editorial Morata.

Giroux, H. A. (2003). La inocencia robada. Juventud, multinacionales y política cultural. Madrid: Editorial Morata.

Góngora, M. (1988). Ensayo histórico sobre la noción de Estado en Chile en los siglos XIX y $X X$. Santiago de Chile: Editorial Universitaria.

González, P., I. Núñez y F. Soto (1997). 160 años de educación pública. Historia del Ministerio de Educación. Santiago de Chile: MINEDUC: 101-180.

Illanes, M. A. (1991). Ausente señorita. El niño-chileno, la escuela para pobres y el auxilio Chile 1890-1990. Santiago de Chile: Junta de Auxilio Escolar y Becas JUNAEB.

Labarca, A. (1939). Historia de la Enseñanza en Chile. Santiago de Chile: Publicaciones de la Universidad de Chile.

Lledó, E. (1996). Lenguaje e historia. Madrid: Editorial Taurus.

Millas, J. (1970). Filosofía del Derecho. Santiago de Chile: Facultad de Derecho. Universidad de Chile y Editorial Universitaria. 
Nef, J. El concepto de Estado subsidiario y la educación como bien de mercado: Un bosquejo de análisis político. Revista Enfoques educacionales. Santiago de Chile. Departamento de Educación, Facultad de Ciencias Sociales, Universidad de Chile, volumen 2, número 2, 19992000. Disponible en http://www.firgoa.usc.es/nodel/10470 (Consultado 2 de abril de 2007).

Núñez, I. (1997). Las Políticas Públicas en Educación, una mirada histórica (1925-1997). Serie Estudios $N^{\circ} 11$. Talca. Instituto de Investigación y Desarrollo Educacional IIDE, Universidad de Talca.

Pacheco Gómez, M. (1988). Teoría del derecho. Santiago de Chile: Editorial Jurídica.

Real Academia Española (RAE). (2001). Diccionario de la lengua española, Madrid: Editorial Espasa-Calpe.

Riveros, L. (2002). Tres momentos históricos de la Universidad de Chile: Andrés Bello, Valentín Letelier, Juvenal Hernández. Discurso pronunciado en el marco del $160^{\circ}$ aniversario de la Universidad de Chile. 20 de noviembre de 2002. Salón de Honor, Universidad de Chile, Santiago de Chile, 9 páginas. Disponible en www.uchile.cl (Consultado el 21 de junio de 2007).

Salas, D. (1917). El problema nacional. Bases para la reconstrucción de nuestro sistema escolar primario. Santiago de Chile: Sociedad Imprenta Universo.

Serrano, S. (1994). Universidad y nación. Chile en el siglo XIX. Santiago de Chile: Editorial Universitaria.

Tadeu Da Silva, T. (1998). Cultura y currículum como prácticas de significación. Revista de Estudios del Currículum $N^{\circ}$ 1, volumen I, enero. Barcelona: Ediciones Pomares-Corredor: 59-76.

Torres, J. (2001). Educación en tiempos del neoliberalismo. Madrid: Editorial Morata.

Yáñez, J. C. (2003). Estado, consenso y crisis social. El espacio público en Chile 1900-1920. Santiago de Chile: Ediciones de la Dirección de Bibliotecas, Archivos y Museos DIBAM. 